Tohoku J. exp. Med., 1972, 107, 105-114

\title{
Residual Catalase in the Blood of Japanese Acatalasemia
}

\author{
Masana Ogata*, Katsumaro Tomokuni*, Shinsaku Watanabe*, \\ Hirokazu Osaki*, Masanori Sadamoto ${ }^{\dagger}$ and Shigeo Takahara ${ }^{\dagger}$ \\ Department of Public Health* and Department of Otorhinolaryn- \\ gology $\dagger$, Okayama University Medical School, Okayama
}

\begin{abstract}
Ogata, M., Tomokuni, K., Watanabe, S., Osaki, H., Sadamoto, M. and Takahara, S. Residual Catalase in the Blood of Japanese Acatalasemia. Tohoku J. exp. Med., 1972, $107(2), 105-114$ - Properties of the residual catalase of erythrocytes in the blood of Japanese acatalasemia are almost the same as those of the normal catalase as judged by the elution pattern by Sephadex $\mathrm{G}-100$ gel filtration, affinity toward the substrate, the sedimentation pattern by density gradient centrifugation, and the heat stability. Japanese acatalasemia is different from Swiss one derived from the literature (Matsubara et al. 1967) on the fact that the residual catalase activity is heat-stable, and the catalase activity in reticulocytes is extremely low in Japanese acatalasemia. The catalase activity of Japanese hypocatalasemia (heterozygote) is also lower than that of Swiss case in the literature (Aebi et al. 1961). The results are discussed in terms of the possible difference in the genetic mechanism of the Japanese and Swiss acatalasemias.

acatalasemia; residual catalase of erythrocytes
\end{abstract}

Acatalasemia found originally in Japan in 1948 by Takahara and Miyamoto (1948) had been considered as an inborn error of metabolism specific to some oriental races (Takahara 1952). Actalasemia was found also in Switzerland in 1961 (Aebi et al.) and was also reported as Takahara's disease in East Germany in 1968 (Düsseldorf et al.).

The name of acatalasemia does not mean a complete lack of catalase activity in the blood. Low catalase activity in the blood has been observed in patients of acatalasemia in both Japan and Swiss by Takahara et al. in 1952 and Aebi et al. in 1961, respectively.

Aebi found residual catalase activity in the hemolysate of Swiss acatalasemia using Sephadex G-100 column chromatography (Aebi et al. 1964), and demonstrated that the residual catalase was present mainly in reticulocytes (Aebi et al. 1966) and less resistant against heat denaturation as compared with the catalase in normal individuals (Matsubara et al. 1967). Feinstein succeeded in getting acatalasemic mouse mutant by irradiation (Feinstein et al. 1964, 1966, 1967 and 1968). We obtained the evidence that residual catalase of mouse acatalasemia was contained mainly in reticulocytes and also unstable against heat denaturation

Received for publication, October 19, 1971. 
(Ogata et al. 1970). The present communication describes the properties of residual catalase in Japanese acatalasemia in comparison with those of Swiss and mouse acatalasemias.

\section{Material and Methods}

Blood: The blood obtained from antecubital vein was heparinized.

Sephadex G-100 column chromatography: The washed erythrocytes were hemolyzed by the addition of four volumes of distilled water. The hemolysate was filtered through a Hyflo Super-Cel column to remove the stroma. One $\mathrm{ml}$ of the filtrate was applied on a column $\left(1.0 \mathrm{~cm}\right.$ in diameter and $143.0 \mathrm{~cm}$ in length, and $V_{o}=34.8 \mathrm{ml}, V i=65.0 \mathrm{ml}$ and $\mathrm{Vt}=106.3 \mathrm{ml}$, by blue dextran method) of Sephadex G-100 (particle size: fine). The elution was carried out with the mixed solution of $0.1 \% \mathrm{NaCl}$ containing $0.75 \%$ chloroform, and $3.2 \mathrm{ml}$ fractions were collected at a flow rate of 8 drops per minute as described by Aebi et al. (1964).

\section{Spectrophotometry: A Beckman DK-2A Spectrophotometer was used.}

$D E A E$ column: Four $\mathrm{ml}$ of washed red cells were hemolyzed by adding $8 \mathrm{ml}$ of distilled water. The hemolysate was dialyzed against $0.001 \mathrm{M}$ phosphate buffer ( $\mathrm{pH} 6.8$ ) overnight. After centrifugation at $20,000 \times \mathrm{g}$ for $40 \mathrm{~min}, 8 \mathrm{ml}$ of the supernatant of the hemolysate were loaded on a DEAE cellulose column $(1.8 \times 15 \mathrm{~cm}, 18.5 \mathrm{~g})$ equilibrated with the $0.001 \mathrm{M}$ phosphate buffer $(\mathrm{pH} \mathrm{6.6)}$. The hemoglobin was eluted with $100 \mathrm{ml}$ of 0.001 M phosphate buffer ( $\mathrm{pH}$ 6.6). The normal catalase as well as the acatalasemic residual catalase appeared after the subsequent elution with $150 \mathrm{ml}$ of $0.1 \mathrm{M}$ phosphate buffer ( $\mathrm{pH}$ 6.8 ) as described by Matsubara et al. (1967). AII procedures were carried out at $4^{\circ} \mathrm{C}$.

Heat stability test: The catalase fractions obtained by the DEAE column chromatography were pooled and adjusted to give the protein concentration of $50 \mu \mathrm{g} / \mathrm{ml}$ by adding $1 \%$ bovine serum albumin solution in $0.1 \mathrm{M}$ phosphate buffer ( $\mathrm{pH}$ 6.8). The incubation was performed in a water bath at $55^{\circ} \mathrm{C}$ for 60 minutes (Matsubara et al. 1967).

Sucrose density gradient centrifugation: Centrifugation was carried out in a linear sucrose density, $5 \%$ to $20 \%$, with a swinging basket of Spinco type preparative centrifuge (Hitachi 50P) at $110,000 \times \mathrm{g}$ for 7 and 5 hours for acatalasemic and hypocatalasemic hemolysates, respectively.

Albumin density gradient centrifugation: The centrifugation was carried out by the method of Sass (1963). Two and half $\mathrm{ml}$ of washed red cell sediment suspended in an equal volume of $26.6 \%$ albumin solution in $0.85 \%$ saline were centrifuged in a swinging basket of Spinco type preparative centrifuge (Hitachi $50 \mathrm{P}$ ). used.

Reticulocyte counts: Supra-vital staining method of Nile blue (Awai $t$ al. 1968) was

\section{Determination of blood catalase activity}

Determination of blood catalase: Perborate method of Feinstein et al. (1949) was used for normal, hypocatalasemic and acatalasemic blood. The method of Takahara et al. (1960) was also used for normal and hypocatalasemic blood.

Determination of catalase in gel fltrate: The modified manometric method of Fujita and Kodama (1930) was used.

Determination of catalase fractions obtained by sucrose density gradient centrifugation: Manometric method was used for acatalasemic hemolysate. The titration method of Takahara et al. (1960) was used for normal and hypocatalasemic hemolysates. 
Determination of blood catalase fractionated by albumin density gradient centrifugation or by DEAE column chromatography: The perborate method of Matsubara et al. (1967) using trichloroacetic acid to remove protein after enzymatic reaction was employed.

\section{Results}

The level of catalase activity in the blood:

The catalase activity of 5 normal individuals in Japan averaged $3,384 \pm 184$ $(\mathrm{m} \pm \sigma) \mathrm{Pu} / \mathrm{gHb}$, being almost similar to that of 12 Swiss children $3,142 \pm 395 \mathrm{Pu} /$ $\mathrm{gHb}$, and also $3,023 \pm 423$ of 60 medical students and technicians reported by Aebi et al. (1961). Residual catalase activity of 5 Japanese acatalasemia averaged $5.5 \pm 0.8$ $\mathrm{Pu} / \mathrm{gHb}$, being almost the same level as that of 5 Swiss actalasemia, $5.9 \pm 3.1 \mathrm{Pu} / \mathrm{gHb}$. Catalase activity of 4 Japanese hypocatalasemia (heterozygote) averaged 1,521 $18 \mathrm{Pu} / \mathrm{gHb}$, which was lower than that of 10 Swiss hypocatalasemia, $1,955 \pm 348$ $\mathrm{Pu} / \mathrm{gHb}$. Log plots of frequency distribution of blood catalase activity are shown in Fig. 1. According to the permanganate titration method of Takahara et al. (1960), the catalase activity in 64 cases of hypocatalasemic Japanese averaged about a half of that in 273 cases of normal Japanese, that is, the mean value was $5.04 \pm 0.68 \mathrm{Kcat}\left(\mathrm{M}_{\mathrm{N}} \pm \sigma_{\mathrm{N}}\right)$ in normal and $2.24 \pm 0.41 \mathrm{Kcat}\left(\mathrm{M}_{\mathrm{H}} \pm \sigma_{\mathrm{H}}\right)$ in hypocatalasemia, and the critical point between the normal and the hypocatalasemic values was 3.29 of Kcat according to the equation of $\left(\mathrm{M}_{\mathrm{N} \sigma_{\mathrm{H}}}+\mathrm{M}_{\mathrm{H}} \sigma_{\mathrm{N}} / \sigma_{\mathrm{N}}\right)$.

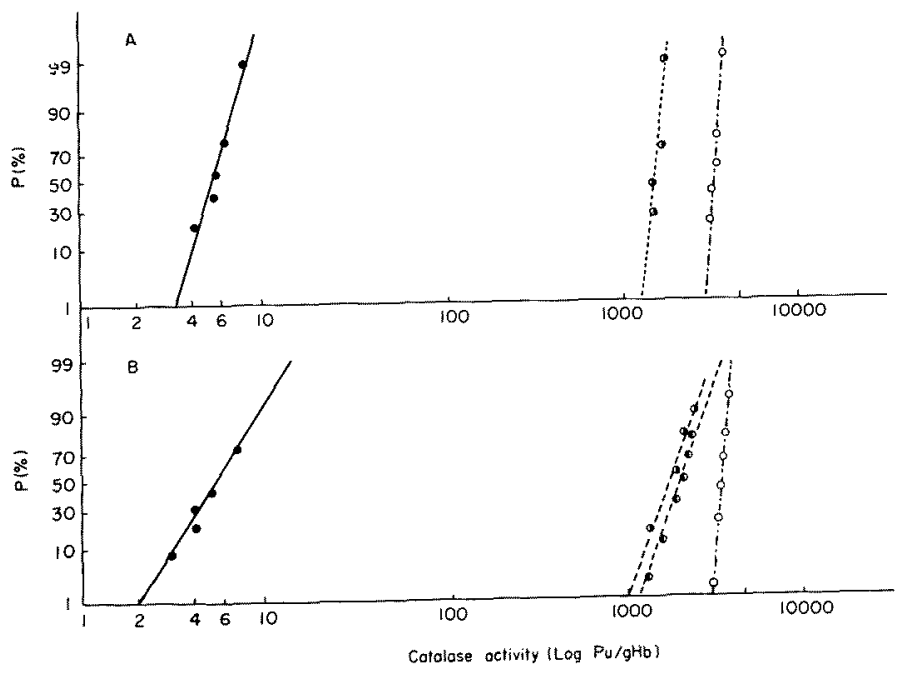

Fig. 1. Long-probit plots of frequency distribution of blood catalase activity in Japanese and Swiss cases. $P=\int_{-B}^{z} \frac{1}{\sqrt{2 \pi}}$ e $\frac{z^{2}}{2} \mathrm{dz}, \mathrm{z}=\log \mathrm{x}, \mathrm{x}=$ actual catalase activity. Fig. 1A. Japanese cases. Fig. 1B. Swiss cases (Aebi et al. 1962-1963). The activity was
determined by the perborate method (Feinstein et al. 1949). Acatalasemia. Carriers on account of genetics. Carriers on account of hypocatalasemia. Control group. 


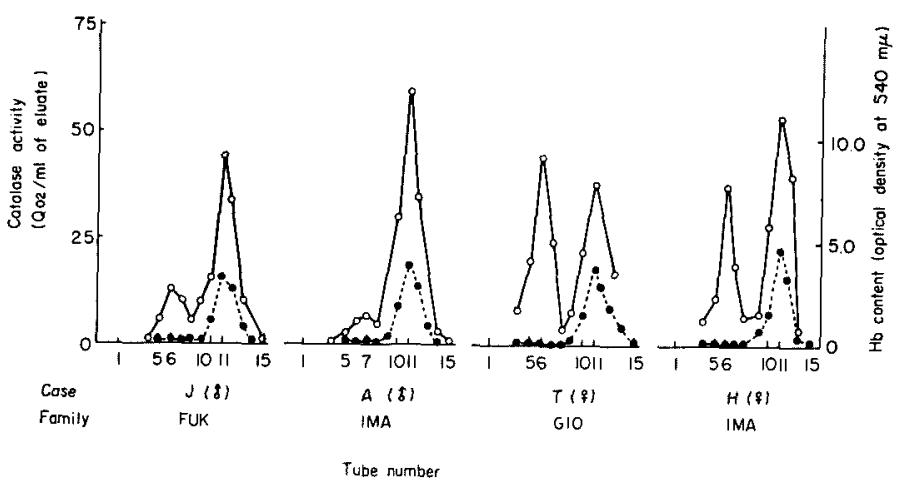

Fig. 2. Separation of residual catalase in the hemolysates of four acatalasemias by Sephadex G-100 gel filtration. _- - Catalase activity. ....... . Hemoglobin concentration. Each tube contained $3.5 \mathrm{ml}$.

\section{Separation of residual catalase by Sephadex G-100 column chromatography}

The chromatographic pattern of the hemolysate showed two peaks of the catalase-like activity in all four cases of acatalasemia (Fig 2).

The fraction comprising the first peak of the catalase activity was thought to be residual catalase, as it was found to the tube number corresponding to one, showing the highest catalase activity in normal hemolysate (Ogata et al. 1968). The second peak of the catalase-like activity was consistent with that of hemoglobin as determined by absorbancy at $540 \mathrm{~m} \mu$ (Fig. 2). The small catalase-like activity in the fractions comprising the second peak was considered to be due to hemoglobin itself, since the formation of methemoglobin-hydrogen peroxide may result in the decomposition to oxygen and water as described by Keilin et al. (1954).

\section{Affinity toward the substrate of residual catalase}

Both the normal and the acatalasemic residual catalase showed similar dependence on concentration of the substrate (Fig. 3). However, the hemoglobin fractions showed lower affinity toward hydrogen peroxide than those of the normal and acatalasemic catalase (Fig. 3). Michaelis constants $(\mathrm{Km})$ of the normal and the residual catalase were 0.35 and $0.37 \mathrm{mM}$, respectively.

On the reaction of methemoglobin with hydrogen peroxide, Keilin et al. (1954) described that the excess of hydrogen peroxide undergoes catalatic decomposition to water and oxygen, and the quantity of hydrogen peroxide added to methemoglobin can be expressed in terms of the molar ratio $(R)$ of hydrogen peroxide to hematin. When $\mathrm{R}$ is 25 or more, bubbles of oxygen arise from the decomposition of hydrogen peroxide. In our manometric study, sufficient oxygen evolution was also observed with the hemoglobin peak fractions at $25 \mathrm{R}$ (Fig. 3).

Heat stability of the residual catalase

The normal blood catalase fraction and acatalasemic residual catalase separat- 


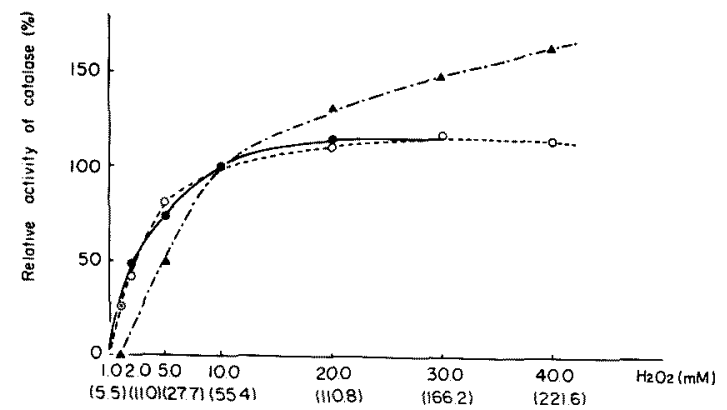

Fig. 3. The relationship between peroxide concentration and relative catalase activity. Substrate-activity curve of normal first peak. ....... That of acatalasemic first peak. - - Acatalasemic hemoglobin peak. The catalase activity obtained at $10 \mathrm{mM} \mathrm{H} \mathrm{H}_{2} \mathrm{O}_{2}$ was taken as $100 \%$. The numbers in brackets represent the molar ratios of $\mathrm{H}_{2} \mathrm{O}_{2}$ to heme of $\mathrm{Hb}$.

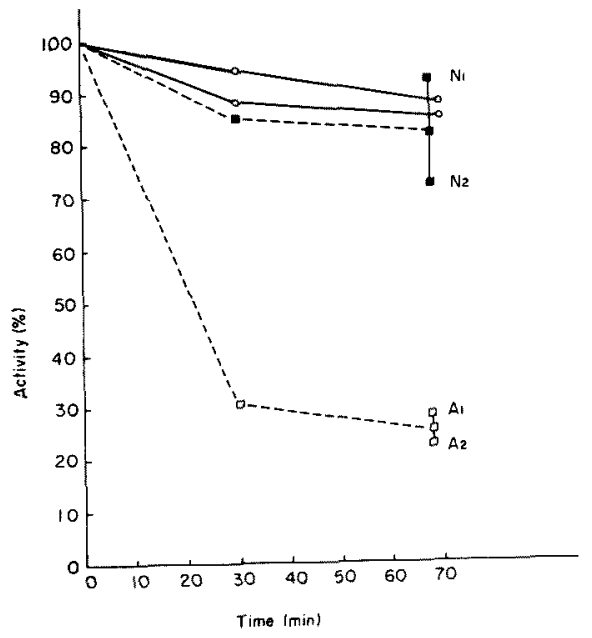

Fig. 4. Heat inactivation of normal catalase fraction and residual catalase fraction from Japanese acatalasemia by DEAE column chromatography after incubation at $55^{\circ} \mathrm{C}$. Catalase activity is measured by perborate method. Ordinate shows the relative catalase activity expressed as $100 \%$ at 0 minute. - Inactivating curve of catalase fraction from hemolysate of normal individuals of Japanese. - $-\mathrm{O}-$ That of Japanese actalasemia. ... - ... That of normal individuals of Swiss (Average of $N_{1}$ and $N_{2}$ fractions). - . - $\square-\cdots$. That of Swiss acatalasemia (average of $A_{1}$ and $A_{2}$ fractions) (Matsubara et al. 1967).

ed by DEAE column chromatography were examined on the heat stability of the enzymic activity. No marked difference was found in the heat stability of the enzyme fraction between normal and acatalasemic blood in Japanese cases (Fig. 4). In the Swiss case reported by Matsubara et al. (1967), the residual catalase activity of the fraction separated by DEAE column chromatography decreased to the level of $25 \%$ of the control, while the catalase activity of the normal fraction 

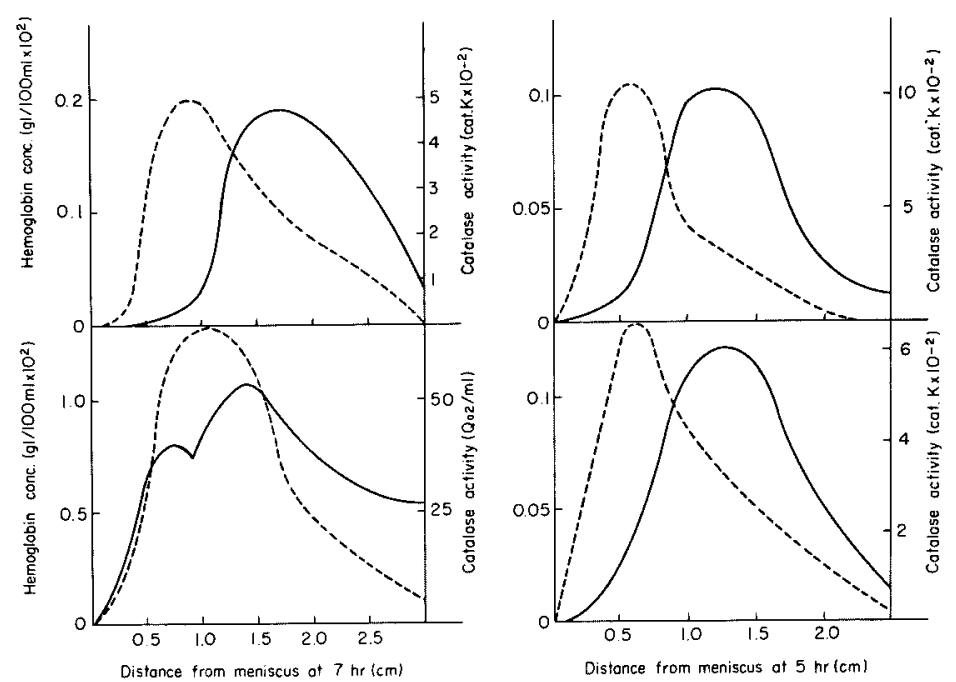

Fig. 5. Sedimentation patterns of the residual catalase of the acatalasemic hemolysate and of the catalase of the hypocatalasemic hemolysate by sucrose gradient centrifugation. Solid line, catalase activity; broken line, hemoglobin concentration.

decreased to $83 \%$, when the fraction was heated at $55^{\circ} \mathrm{C}$ for 60 minutes in the same way as the residual catalase of Japanese acatalasemia was treated. Therefore, the residual catalase of Swiss acatalasemia was less stable to heat than that of 2 cases of Japanese acatalasemias in $(\mathrm{N})$ family.

\section{Sucrose density gradient centrifugation}

The distribution pattern of catalase-like activity of the acatalasemic hemolysate showed two peaks, the faster peak due to catalase activity of residual catalase and the slower peak due to catalase-like activity of hemoglobin. The former had almost the same sedimentation velocity as that of the normal catalase, though the value of the former was slightly less than that of the latter (Fig. 5). The sedimentation velocity of the catalase of the hypocatalasemic blood was almost the same as that of the normal catalase (Fig. 5).

Fractionation of red cells of the acatalasemic blood by albumin density gradient centrifugation

The distribution of the residual catalase activity in the albumin density gradient fractions of the blood obtained from 4 cases of acatalasemia is shown in Fig. 6. The abscissa indicates the distance from the surface of sediment to each fraction and the ordinate shows the reticulocyte counts and residual catalase activity as represented by $\mathrm{Qo}_{2} / \mathrm{mg} \mathrm{Hb}$ (manometric method) and $\mathrm{Pu} / \mathrm{gHb}$ (perborate method), respectively. The numbers of reticulocytes were larger in the upper layer and smaller in the lower layer, and the residual catalase activity of 


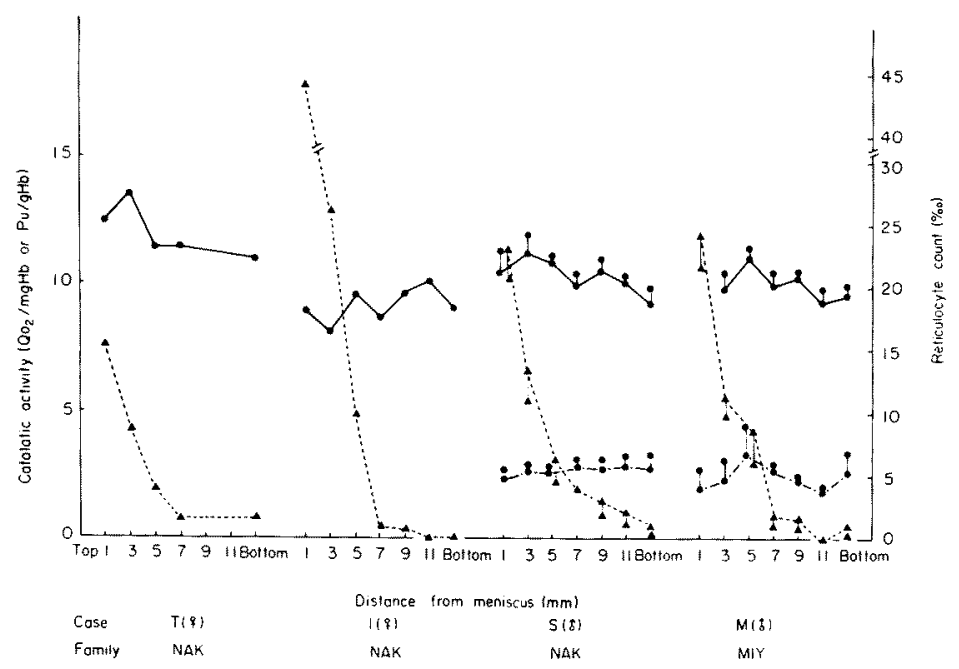

Fig. 6. Reticulocyte count and residual catalase activity of the fractions from Japanese acatalasemic blood specimens taken from three cases in one family and one case in another family. Catalase activity determined by the manometric method. - - _ - Catalase activity determined by the perborate method. .......

Reticulocyte count. Figures for the cases $\mathrm{S}$ and $\mathrm{M}$ represent average \pm S.D.

each fraction in 4 cases did not show any significant difference by the manometric and perborate methods.

\section{Discussion}

The residual catalase separated by Sephadex G-100 gel filtration showed the affinity for the substrate similar to that of the normal catalase. The residual catalase separated by DEAE column chromatography exhibited also the heat stability similar to that of the normal catalase. The sedimention velocity of the residual catalase was also the same as that of the normal catalase. These results indicate that the residual catalase has essentially the same physicochemical property as that of the normal one. Therefore, it is suggested that the residual catalase activity present in the acatalasemic red cells is due to the catalase protein itself.

In acatalasemia, the enzyme deficiency is not complete. If catalase does play an essential role in life, the residual enzymic activity seems to be sufficient. Furthermore, there is good evidence that lack of catalase can be sufficiently compensated. In the red cells, this is done by glutathione peroxidase (Aebi et al. 1964). Therefore, the individuals of Japanese acatalasemia lead normal life, except that about a half of the patients of actalasemia has oral gangrene. When the patients of acatalasemia are infected with pneumococci or streptococci which yield hydrogen peroxide, the compensations by the residual catalase, glutathione peroxidase and methemoglobin hydrogn peroxide compound are not enough to decompose hydrogen peroxide, and the oral gangrene may be caused (Takahara et 
TABLE 1. Difference among Japanese acatalasemia, Swiss one and radiation induced mouse one

\begin{tabular}{|c|c|c|c|}
\hline & $\begin{array}{l}\text { Distribution of } \\
\text { cata. activ. }\end{array}$ & $\begin{array}{l}\text { Heat stability com- } \\
\text { pared with normal }\end{array}$ & $\begin{array}{l}\text { Locus of } \\
\text { mutation }\end{array}$ \\
\hline $\begin{array}{l}\text { Japanese } \\
\text { acatalasemia }\end{array}$ & $\begin{array}{l}\text { Almost equal in } \\
\text { reticulocytes and ma- } \\
\text { tured erythrocytes }\end{array}$ & Stable & $\begin{array}{l}\text { In control or } \\
\text { structure gene }\end{array}$ \\
\hline $\begin{array}{l}\text { Swiss acatalasemia } \\
\text { by Aebi }\end{array}$ & $\begin{array}{l}\text { A greater part in } \\
\text { reticulocytes }\end{array}$ & Less stable & $\begin{array}{l}\text { At least in } \\
\text { structure gene }\end{array}$ \\
\hline $\begin{array}{l}\text { Radiation induced } \\
\text { mouse acatala- } \\
\text { semia* }\end{array}$ & $\begin{array}{l}\text { Mostly in } \\
\text { reticulocytes }\end{array}$ & Less stable & $\begin{array}{l}\text { At least in } \\
\text { structure gene }\end{array}$ \\
\hline
\end{tabular}

* Donated by courtesy of Dr. Feinstein, R.N.

al. 1948). In our results (Ogata and Takahara 1968), the catalase activity in the fraction of the first peak obtained by gel filtration was $11.8,6.3$ and $20.3 \mathrm{Qo}_{2} / \mathrm{ml}$ in severe patients, $45.0 \mathrm{Qo}_{2} / \mathrm{ml}$ in a mild patient, and 52.8 and $40.5 \mathrm{Qo}_{2} / \mathrm{ml}$ in symptomless patients. These results indicate that the residual catalase may play some role in preventing the oral gangrene by pneumococcus and streptococcus.

In Japanese acatalasemia, the residual catalase activity in reticulocytes is very low, but the catalase itself is heat-stable and does not show any difference from the catalase of the normal subject (Table 1). In Swiss acatalasemia, in which the catalase activity in reticulocytes is extremely high, the catalase is heat-unstable, and the low catalase activity results mainly from the decrease in catalase in the red cells after maturation (Aebi et al. 1966). In the radiation-induced mouse acatalasemia, the residual catalase activity present mainly in the reticulocyte decreased during the cell maturation (Ogata et al. 1970).

In the hereditary disorder of acatalasemia, the structural and control gene mutations could be taken into consideration. As to the pathogenesis of acatalasemia, the control gene mutation was suggested by Parker and Bearn (1963). In contrast to this, Epstein (1964) described that in the disease due to deficiency in enzyme, locus of mutation of gene can be explained only as the structural gene mutation.

Structural gene mutation represents an alteration of the template which carries the coded information for the primary structure of polypeptide chain, and the alteration of the normal sequence of amino acid of enzyme protein must be modulated like many hemoglobin variants.

From this point of view, the mutation of locus of Japanese, Swiss and mouse acatalasemias will be discussed on the basis of properties of the residual catalase. From the results showing that the residual catalase activity exists mainly in reticulocytes and the residual catalase is more heat-unstable than the normal catalase, the involvement of the structural gene mutation is suggested in cases of Swiss and mouse acatalasemia. But the mechanism of development of Japanese acatalasemia is completely obscure at present. Some defect in the 
process of the gene expression could be expected. If the control gene is proved to be present in the mammalian system with allelism, the possibility of mutation of the control gene should be taken into consideration in the case of Japanese acatalasemia. A structural gene mutation corresponding to the catalase molecule would effect the catalase protein biosynthesis and would not be effective in the synthesis of a protein which accelerates the degradation of catalase molecules in vivo.

\section{Acknowledgment}

We thank Dr. H. Taniuchi, Laboratory of Chemical Biology, National Institute of Health, Bethesda, for discussion and criticism of this manuscript.

\section{References}

1) Aebi, H., Heiniger, J.P., Bütler, R. \& Hässig, A. (1961) Two cases of acatalasia in Switzerland. Experientia, 17, 466.

2) Abei, H., Jeuner, F., Richterich, R., Suter, H., Bütler, R., Frei, J. \& Marti, H.R. (1962-1963) Observations in two Swiss families with acatalasemia. Enzym. biol. clin., 2, 1-22.

3) Aebi, H., Baggiolini, M., Dewald, B., Lauber, E., Suter, H., Migheli, A. \& Frei, J. (1964) Observations in two Swiss families with acatalasemia. Enzym. biol. clin., 4, 121-151.

4) Aebi, H. \& Cantz, M. (1966) Über die cellulare Verteilung der Katalase im Blut homozygoter und heterozygoter Defektträger (Akatalasia), Humangenetik, 3, 50-63.

5) Awai, M., Okada, S., Takebayashi, J., Kubo, T., Inoue, M. \& Seno, S. (1968) Studies on the mechanism of denucleation of the erythroblast. Acta. haemat., 39, 193202.

6) Düsseldorf, K.K. \& Heidelberg, H.O. (1968) Akatalasia bei einem vierjährigen Jungen. Kinderärztl. Prax., 8, 367-370.

7) Epstein, C.T. (1964) Structural and control gene defects in hereditary diseases in man. Lancet, 2, 1066-1067.

8) Feinstein, R.N. (1949) Perborate as substrate in a new assay of catalase. J. biol. Chem., 180, 1197-1202.

9) Feinstein, R.N., Seaholm, J.E., Howard, J.B. \& Russell, W.L. (1964) Acatalasemic mice. Proc. nat. Acad. Sci., Wash., 52, 661-662.

10) Feinstein, R.N., Howard, J.B., Braun, J.T. \& Seaholm, J.E. (1966) Acatalasemic and hypocatalasemic mouse mutants. Genetics, 53, 923-933.

11) Feinstein, R.N., Braun, J.T. \& Howard, J.B. (1967) Acatalasemic and hypocatalasemic mouse mutants. II. Mutational variations in blood and solid tissue catalases. Arch. Biochem., 120, 165-169.

12) Feinstein, R.N., Braun, J.T. \& Howard, J.B. (1968) Nature of the heterozygote blood catalase in a hypocatalasemic mouse mutant. Biochem. Genet., 1, 277-285.

13) Fujita, A. \& Kodama, T. (1930) Manometrische Bestimmung der Katalase. Biochem. Z., 232, 20-34.

14) Keilin, D. \& Hartree, E.F. (1954) Reaction of methemoglobin and catalase with peroxides and hydrogen donors. Nature, 173, 720-723.

15) Matsubara, S., Suter, H. \& Aebi, H. (1967) Fractionation of erythrocyte catalase from normal, hypocatalatic and acatalatic humans. Hum. Genet., 4, 29-41.

16) Ogata, M. \& Takahara, S. (1968) On minimal catalatic activity of Japanese acatalasemia and acatalasemic mice. Proc. 12th int. Congr. Genetics, 1, p. 151.

17) Ogata, M., Inoue, T., Tomokuni, K. \& Takahara, S. (1970) Catalase activity of immature and mature red cells from acatalasemic mouse mutant. Acta. haemat., 44, 
$11-20$.

18) Parker, W.C. \& Bearn, A.G. (1963) Application of genetic regulatory mechanisms to human genetics. Amer. J. Med., 34, 680-691.

19) Sass, M.D. (1963) Catalase activity in young red cells. Nature (Lond.) 197, 503-504.

20) Takahara, S. \& Miyamoto, H. (1948) Clinical and experimental studies on the odontogenous progressive necrotic ostitis due to lack of blood catalase. $J$. othorhi. Soc. Jap., 51, 163-164.

21) Takahara, S. (1952) Progressive oral gangrene probably due to lack of catalase in the blood (acatalasaemia). Lancet, 263, 1101-1104.

22) Takahara, S., Hamilton, H.B., Neel, J.V., Kobara, T.Y., Ogura, Y. \& Nishimura, E.T. (1960) Hypocatalasemia: A new genetic carrier state. J. clin. Invest., 39, 610619 . 